\title{
Jahrestagung 1983
}

Die Jahrestagung 1983 fand vom 28. September bis 1. Oktober in Köln statt. Den Vorsitz führte Peter Lerche. Die Diskussionsleitung zum 1. Beratungsgegenstand lag in der Hand des Vorstandsmitglieds Walter Schmitt Glaeser, die Aussprache zum 2. Beratungsgegenstand leitete das Vorstandsmitglied Eberhard Schmidt-Aßmann.

Seit der letzten Jahrestagung sind zwölf Kollegen neu in die Vereinigung aufgenommen worden. Die Vereinigung zählt nunmehr 326 Mitglieder. Davon haben an der Tagung 218 teilgenommen, zum großen Teil mit ihren Ehefrauen. Außerdem konnten auch in diesem Jahr wieder eine Reihe ausländischer Gäste und die Vertreter der deutschen Fachzeitschriften begrüßt werden.

In der Mitgliederversammlung wurde der verstorbenen Mitglieder Günther Küchenhoff und Walter Mallmann gedacht. Die nächste Jahrestagung wird vom 3. bis 6. Oktober in Göttingen stattfinden. Als neuer Vorstand wurde in geheimer Wahl gewählt: Hans Heinrich Rupp, Peter Häberle, Hans-Uwe Erichsen.

Am ersten Abend wurden die Teilnehmer mit ihren Damen durch den Herrn Bundespräsidenten, Professor Dr. Karl Carstens, im Schloß Brühl empfangen. Am zweiten Tag waren sie Gast des Oberbürgermeisters im historischen Rathaus der Stadt Köln. Nach Abschluß des wissenschaftlichen Programms traf sich die Vereinigung zu ihrem traditionellen festlichen Gesellschaftsabend, der dieses Mal seine besondere Note durch die musikalischen Darbietungen von Mitgliedern der Oper der Stadt Köln erhielt. Die Tagung klang aus mit einem gemeinsamen Besuch des Kölner Doms am Samstag vormittag. Er stand unter der kundigen Führung des Dombaumeisters Dr. Arnold Wolff und wurde musikalisch umrahmt durch ein Orgelkonzert des Domorganisten Professor Joseph Zimmermann.

Die Tagung war ebenso sorgfältig wie phantasievoll vorbereitet und organisiert. Der besondere Dank dafür gilt der gastgebenden Fakultät, allen voran Herrn Klaus Stern und seiner Gattin sowie allen seinen Mitarbeiterinnen und Mitarbeitern.

Die nachstehend abgedruckten Referate wurden am 29. und 30. September in der Universität gehalten. Dort fanden auch, jeweils an den Nachmittagen, die Aussprachen statt. 
